\title{
La acedia como forma de malestar en la sociedad actual
}

\author{
María Lucrecia Rovaletti*1
}

Martín Pallares*2

Partiendo de la propuesta de Theunissen, se busca realizar un regreso arqueológico respecto al concepto de melancolía en la antigüedad y de acedia medieval. Con ello, se intenta reflexionar esa trama de fatiga, aburrimiento, tedio, tristeza que se entreteje en la cultura actual. Charbonneau y Legrand (2003) designan como paradepresiones a este conjunto de problemas a menudo infrasintomáticos, demasiado lábiles y poco significativos para ser denominados sintomas.

Palabras claves: Melancolía, acedia, sociedad moderna

*1 Universidad de Buenos Aires - UBA-CONICET (Buenos Aires, Ar)

*2 Universidad de Buenos Aires - UBA (Buenos Aires, Ar) 
...la acedia está esencialmente ligada a una dimensión temporal, y aún propiamente histórica del sufrimiento humano personal, pero también al modo de malestar de la civilización.

(Forthomme, 2003, 22).

La acedia constituye históricamente una temática menos antigua que la melancolía, y no ligada a la historia médica como ésta. A pesar de ello, ha ocupado el lugar de la melancolía aunque no lo ha hecho del mismo modo ni en el mismo contexto: ya no se trata del entorno naturalista de Hipócrates sino de un orden teológico.

Actualmente la acedia se presenta ante todo como un tema de filosofía moral, de moral religiosa y de antropología filosófica (Legrand, 2003b, p. 98).

Aplicado a la patología, el vocablo acedia no siempre ha sido bien definido y a menudo se lo considera obsoleto. Sin embargo, su etimología puede ofrecernos interesantes aportes.

El verbo griego Kédo indica perjudicar, herir, turbar. En forma pronominal indica inquietarse por, estar inquieto, cuidar de. Como sustantivo, Kédos significa cuidado, inquietud, sobre todo en dos usos particulares: por un lado duelo, honores dados a un muerto y por otro, unión, parentesco por alianza.

Pero también el adjetivo a-kedés se refiere al descuidado, al que no se ocupa, aquel al que no se le dan honores fúnebres, como ocurre en los escritos homéricos. El sustantivo akedia aparece en el griego tardío, y lo utiliza Cicerón y la versión griega de la Biblia. Se la traduce como tristeza, aflicción. En los escritos de los primeros cristianos, esta aflicción tiene un matiz de desaliento.

Originariamente, la acedia se presenta como una experiencia solitaria en los eremitas del desierto egipcio - es el caso de Evagrio (siglo IV), y luego con algunas transformaciones en la monástica comunitaria (Casiano, los Cenobíticos). Posteriormente, la acedia va dispersándose al 
producirse una mutación de la vida religiosa en el siglo XIII ligada a la urbanización y al disminuir la vida monástica con la Reforma del siglo XVI, hasta desaparecer con la Revolución francesa. En este sentido, Pinel considera que este tipo de vida constituía para la salud un foco de melancolía.

Desde el siglo XVIII la acedia se asocia a nivel pastoral a la melancolía, lo cual permite excusar a aquellos que la sufren alegando que ese sustrato fisiológico de la afección es independiente de la libertad personal. La acedia deviene así un sinónimo de tristeza, una tristeza que paraliza el trabajo productivo, pero sobre todo el amor al Otro, a los otros y a sí mismo.

A pesar de estos avatares, el ideal de perfeccionamiento individual no desaparece, aunque se puede observar un deslizamiento mayor al pasar al ámbito de la vida práctica, y luego al libidinal.

La acedia no puede ser entendida jamás como simple depresión, dado que está ligada al menos originariamente a la búsqueda de un modelo elevado de vida, a una ambición espiritual o profesional sostenida. Ambición de devenir si mismo, de hacerse cargo de si, de no aceptar sino una constricción interior, pero de una fuerza mas grande que las presiones biológicas, psicológicas o sociales, aún históricas (Forthomme, 2003b, p. 22).

Mas aún, aunque la acedia se relaciona con la melancolía por la dimensión de tristeza y hasta tal punto que pareciera confundirse con ella, es necesario señalar que ésta presenta una forma particular de sufrimiento con una falla masiva en la autoestima de si, un enlentecimiento psicomotor, y una temporalidad que se expresa en la queja y el fracaso constante que afecta a la constitución misma de su estructura mundana. En la acedia, por el contrario hay una duda sobre el sentido de las cosas, una interrogación permanente del para qué, que sumerge al sujeto en la indiferencia hasta la pereza y la aflicción.

Precisamente, en la cultura actual puede encontrarse una trama de fatiga, aburrimiento, tedio, tristeza... Estas afectaciones de la motivación que nos llevan al no-sentido, puede encontrarse en grados y formas diversas, son designadas por Charbonneau y Legrand como paradepresiones. ${ }^{1}$

${ }^{1}$ Conviene insistir que no todo sufrimiento implica necesariamente un elemento depresivo: existe un conjunto de problemas de insatisfacción, crisis de sentido, abatimiento, que no son depresivos. Por otra parte, una pseudo-depresión no es lo mismo que para-depresión. Pseudo indica algo que no es verdaderamente tal, y puede incluirse en variadas patologías. Para, en cambio indica algo preciso, un alrededor de: hay tristezas transitorias que no son depresiones y no pertenecen a las patologías; algunas requieren de cuidados, pero no constituyen enfermedades. Finalmente, debe distinguirse la pre-depresión como estadio previo de una patología depresiva. 
"La paradepresión no es de esencia médica sino llega a ser una ética, una manera de vivir, que se inserta en la corriente de una época" (Debray, 2003b, p. 13).

Sin embargo, a diferencia de otros estados afectivos como la angustia o la depresión, estos problemas se mantienen al margen de una reflexión teórica. Más aún, su "banalidad", su cotidianidad, su constante referencia al contexto social del sujeto que los vivencia han contribuido a excluirlos de una categoría psico(pato) lógica autónoma y del interés clínico (Maggini y Dalle Lucche, 1991).

Ahora bien, para reflexionar sobre esta temática es preciso profundizar una gesta arqueológica que permita comprender nuestra época. Como señala Theunissen (2005), los "conceptos que durante siglos han sido trasmitidos, redefinidos y desgastados pueden ser explicados únicamente remontándonos hasta su origen" (p. 21). Por ello, se retoman los conceptos de melancolía antigua y de acedia cristiana en la medida que pueden constituir "anteproyectos de la modernidad" actual (idem). En otras palabras, se trata analizar qué hay de "moderno" en las concepciones de melancolía y acedia de la antigüedad clásica y del medioevo (Pocai, 2005, p. 10), pero también como éstos se profundizan en los planteos heideggerianos sobre aburrimiento y tedio, y en la respuesta de Levinas en términos de paciencia.

\section{Primer anteproyecto. La melancolía entre lo extraordinario y lo extraño, y la acedia entre la debilidad del alma y la pereza ante los deberes}

Cuando Teofrasto se pregunta en los Problemata $X X X$ por qué todos los hombres que sobresalen (perittoi) son melancólicos, está interrogándose cómo algo negativo como la melancolía puede posibilitar algo positivo. Establece así el carácter dialéctico entre la constitución melancólica y la posterior enfermedad en tanto aumento de una anomalía. A fin de contrarrestar esta situación propone una moderación del exceso que se acerque a un término medio como única forma de vida exitosa para el melancólico.

Esto lo lleva a indagar también cómo pueden los melancólicos relacionarse con los hombres comunes, encontrando la respuesta en que ambos comparten una dimensión común. De este modo, eleva a la melancolía a un estatuto antropológico. Más aún, plantea que ésta en su forma natural puede dar lugar a la enfermedad o a las grandes obras.

Se observan aquí dos dialécticas que dan cuenta de la modernidad. Por un lado, la melancolía se presenta como algo negativo que posibilita algo positivo: la melancolía encierra lo extraordinario y lo extraño (Theunissen, 2005, p. 32). Por 


\section{ARTIGOS}

otro, que todos los hombres poseen algo de melancolía, y puede desencadenarse una anomalía por exceso de la bilis negra: la melancolía se extiende entre la depresión y la manía. El remedio será el control del exceso hacia la moderación de la bilis negra. Analizando la melancolía, se pueden distinguir cuatro momentos: en su modalidad natural, en su conversión en enfermedad, como posibilidad sobresaliente de rendimientos y como disposición melancólica. Precisamente, aquí puede plantearse "el 'acta de nacimiento' de la psicopatología moderna", según Pocai $(2005$, p. 1)

Por su parte, el término "acedia" constituye una versión latinizada de la palabra griega akédia (a-kédia), es decir la negación de kêdos (cuidado), descuido o falta de cuidado. Hacia el siglo II la figura de Evagrio Póntico (345-399), asceta cristiano, escritor y orador, la ubica como uno de los ocho pecados que acechan al monje: gula, lujuria, avaricia, tristeza, vanagloria, ira, orgullo y acedia. En su obra "Sobre los ocho espíritus malignos" señala que, "La acedia es la debilidad del alma que irrumpe cuando no se vive según la naturaleza ni se enfrenta noblemente la tentación (...) [el acidioso] se fatiga inútilmente" (Evagrio Póntico, 2010).

La "acedia" se presenta ahora desde una perspectiva teológica. Es el demonio del mediodía ${ }^{2}$ que inunda al monje, lo aleja de la alegría y dicha de Dios. El acidioso se torna flojo, débil y perezoso en los deberes monásticos. Genera impotencia de la voluntad y obtusidad del intelecto, esa suprema facultad espiritual del hombre, núcleo más profundo del alma. Se olvida de los grandes beneficios de Dios, de su amor, de sus juicios, y al mismo tiempo se disgusta por sus dones; ignora los males humanos y, por lo tanto, la necesidad de ser salvados.

Por ello, para poder retornar a la búsqueda de Dios, uno debe recurrir a la paciencia y a la actividad. Sólo asumiendo el trabajo concienzudo de la meditación (constancia) y la penitencia (temor a Dios) se fecunda la capacidad de acoger las mociones de la gracia y los signos de Dios.

Evagrio establece que la cura de la acedia era el hacer paciente. El trabajo, y el rezo prudente y con fuerza hacen que la acedia escape de nosotros. Propone entonces una resolución de carácter ético ante la tentación del demonio del mediodía. Sólo la paciencia, esa acogida resistente que permite mostrar una cualidad distinta de la experiencia, puede servir de remedio. Pero ello requiere un aprendizaje, un hábito de otro tipo: la perseverancia en las tareas frente a la desmesura.

${ }^{2}$ Para Rohde, este demonio no es sino una reencarnación de Empusa, criatura fantástica del folclore griego antiguo. Al comienzo representaba una diosa de la vida, pero posteriormente devino una diosa lúgubre que funciona como vampiresa que se acerca al hombre dormido, bebe su sangre y lo desvitaliza (Agamben, 1995, p. 23) 
A diferencia de Evagrio, Casiano el Romano (360-435) valoriza la vida monacal en comunidad y considera que la anacoresis sólo es posible para aquellos almas ya purificadas de los vicios, es decir después de las renuncias al cuerpo, a las riquezas y bienes del mundo, a la vida pasada, a las pasiones del espíritu y la carne, hasta el retirar nuestro espíritu de las cosas presentes y visibles para contemplar únicamente las cosas por venir y no desear sino las invisibles.

La acedia, ese taedium o ansiedad del corazón se experimenta en solidario. A diferencia de Evagrio, Casiano se posiciona de modo diferente frente a la tristeza. Hay una tristeza mala, pero también otra buena. Ésta última motiva al arrepentimiento y a la perfección, y resulta comprensible ante la toma de conciencia de nuestras faltas. Finalmente, hay una tristeza inmotivada que se emparenta con la desesperanza y entonces es un insulto a la omnipotencia de la gracia divina. Cassiano presenta así un análisis penetrante, mostrando la importancia de los sentimientos inconscientes, en tanto faltas que provienen de nosotros y no de algo externo. Para prevenir la acedia y la tristeza, cercanas ambas, propone el orar y trabajar.

Un siglo después, Gregorio de Niza suprime la acedia de la lista de pecados capitales, porque allí se confunde la tristeza con la pereza, pero fundamentalmente porque la considera un estado mórbido, relevante en el ámbito médico. Su preocupación por el conocimiento del hombre le permite una serie de aportes psicológicos, teniendo en cuenta la debilidad humana pero también la responsabilidad ante el pecado.

\section{Segundo anteproyecto: La acedia desde la perspectiva moral y antropológica}

En la Edad Media, el concepto de acedia continúa mostrándose como un peligro catastrófico para el alma humana, llegando a tornarse en el peor de los pecados capitales, aunque en la escolástica se la incluye como género de la tristitia (tristeza). En el siglo XIII, Tomás de Aquino ${ }^{3}$ la define como tristitia spiritualis boni y confrontando con la tradición, concluye:

${ }^{3}$ Theunissen dejando de lado la lectura teológica de la acedia que hace Santo Tomás, plantea aquí una comprensión filosófica de la misma. Desde la perspectiva de la libertad del hombre, considera a la acedia como expresión de una pérdida basal de experiencia, originada en las primeras formas de vida ascética, dedicada por completo a Dios (Theunissen, 2005, pp. 13-14). 


\section{ARTIGOS}

(...) un descuido (A-kédia) que, en tanto que despreocupación respecto a aquello de lo que verdaderamente nos deberíamos preocupar, viene acompañado de lo contrario: la carga de la que dispensa retorna en él como una molestia. (...) la acedia se manifiesta en el taedium, una aversión que puede llegar hasta el asco, y que a menudo se convierte en apatía. (Theunissen, 2005, p. 47)

La acedia como tristeza hacia lo bueno espiritual constituye la contrapartida del verdadero gozo. La acedia es,

(...) una especie de angustioso vértigo que acomete al hombre cuando se da cuenta de la altura adonde lo eleva Dios. El hombre afectado de "acedia" no tiene ni el ánimo ni la voluntad de ser tan grande como realmente es. Preferiría empequeñecerse para sustraerse de este modo a la obligación de la grandeza. La "acedia" es una humildad pervertida; no quiere aceptar los bienes sobrenaturales, porque implican esencialmente una exigencia para el que los recibe. (Pieper, 1976, p. 395)

Es esa despreocupación de lo importante, que más que permitir un descanso ante la ardua tarea de acercarnos a Dios, deviene carga como molestia, pesadez, impotencia, hasta taedium; a menudo acaba en torpor, una debilidad que se convierte en apatía e inmovilización del cuerpo.

Ahora bien Tomás de Aquino, al incluir la acedia como tristitia reelabora este término como pasión, y la acerca a la teoría médica de los temperamentos. ${ }^{4}$ En el contexto de las pasiones, la acedia se torna más un proceso mórbido que una falta moral. Sin embargo, sólo la acedia como tristitia aggravans, es decir en su aspecto depresivo tendrá relevancia psicopatológica, dado que se constituye un abatimiento que no remite a nada significante. Más aún, sólo puede caer en el abismo de la acedia quien se encontraba en la cima de esta alegría. Esta huída de Dios, esta verdadera separación dramática conlleva una tranquilidad "prohibida": la apatía.

El Aquinate además, rechaza considerar la acedia como sinónimo de pereza. ${ }^{5}$ Al contrario, este fenómeno queda referido a Otro: "Es una experiencia de Dios,

${ }^{4}$ Tomás de Aquino distingue once pasiones distintas. Seis corresponden en el apetito concupiscible, como el amor, el odio, el deseo o la concupiscencia, la aversión, el deleite o el gozo, el dolor o la tristeza; otras cinco al apetito irascible como la esperanza, la desesperación, el temor, la audacia y la ira (Manzanedo, 2004, p. 32).

${ }^{5}$ En este sentido, Agamben muestra cómo la psicología moderna se encargó de vaciar a la acedia de su significado original, y de convertirla en un sinónimo de "pecado contra la ética capitalista de trabajo". 
pero en el modo de negación" (Theunissen, 2005, p. 48). La acedia no es melancolía; en este segundo anteproyecto, se atribuye a la acedia el carácter de descuido de Dios, lo cual lo protege frente a la desaparición del Otro negado en la melancolía. La tristeza que retorna como molestia (tristitia spiritualis boni) es provocada por la imprudencia que otorga la libertad por la auto-separación de la fuente de alegría. En el Dios que se retira, en esa alegría perdida, se anuncia el nihilismo de la modernidad: en un mundo despojado de lo divino, la acedia me instala en él de un modo distinto: me abre a mi propia realidad y a tener que hacerme cargo de ella por mis propias fuerzas.

El epílogo puede ser entonces una huída hacia el mundo, como intento de escapar de la tristeza a través de ciertas satisfacciones mundanas. Pero Tomás de Aquino también prevé mediante prolongadas meditaciones una resistencia constante, es decir una cogitatio perseverans a fin de recuperar la alegría perdida.

Por ello en la tradición medieval, la paciencia y la perseverancia constituyen el remedio ante la acedia. Pero no se trata de buscar remedio en el activismo del sobre-trabajo, ya que la acedia no es una fatiga o cansancio por el trabajo, sino una fatiga que se vuelve tedio. En efecto, la paciencia y la acedia participan de un mismo movimiento (retención acética/protección paciente): no hay paciencia sin amenaza incesante de la acedia. La paciencia deviene la solución entre acedia y perseverancia.

En síntesis. La acedia constituye una noción bipolar: implica una noción de pena, tristeza y a su vez de pereza, de relajación, aflojamiento y a menudo de aburrimiento, como ocurre con Evagrio y Casiano. Por el contrario, al desaparecer la acedia entre los pecados capitales, subsiste la tristeza y cubre de algún modo el campo de la acedia.

\section{Tercer Proyecto. Cuando una silenciosa niebla nivela todo en una extraña indiferencia}

El aburrimiento profundo va rodando por las cimas de la existencia como una silenciosa niebla y nivela a todas las cosas, a los hombres, y a uno mismo en una extraña indiferencia.

(Heidegger, 1955, p. 39).

El estado de ánimo es "la forma de ser original del Dasein en cuanto abierto para sí mismo", dirá Heidegger en Ser y tiempo (1927). Siempre y en cada situación se está en un cierto "temple de ánimo", y esto muestra la condición afectiva de nuestro ser-en el mundo. En este "andar por" (Umgang) el mundo en las múltiples formas de ocupación (Besorgen), las "cosas de la vida" o "asuntos" se nos 


\section{ARTIGOS}

presentan no como meros datos objetivos, sino como temibles, gozosos, dolorosos, angustiantes...

Habitualmente, estas disposiciones anímicas se trivializan como estados de ánimo pasajeros, indicativos de la mayor o menor gravedad de las cosas que nos pasan. Sin embargo, los estados de ánimo tienen ontológicamente la función de "abrirnos" a nuestro propio ser, dándonos a entender nuestra situación original de ser-en-el-mundo: a su "facticidad", es decir que el Dasein "es" y "que ha de ser", aunque el "de donde" y el "a donde" permanezcan en la oscuridad.

En el curso "¿Qué es la metafísica?" de 1929-1930, Heidegger señala que preguntarse quiénes somos hoy y cuál es la esencia de nuestra modernidad, es responder por nuestro temple. Plantea entonces el "aburrimiento" como un estado de ánimo vinculado al vacío, algo que la modernidad precisamente rehúsa tratar, por lo cual éste deviene aborrecimiento, como señala la etimología latina. ${ }^{6}$

Heidegger analiza este temple afectivo que corresponde al hombre actual (das heutige Dasein) para poder llegar al temple ánimo fundamental (Grundstimmung).

Ante la aparición de una industria del ocio, el aburrimiento se muestra como aquello ante lo cual continuamente uno se escapa, determinando en forma negativa nuestra existencia, como un trasfondo que nos acecha. El aburrimiento, "Langeweile", ese "rato largo", es lo que le permite a Heidegger relacionarlo con la dimensión temporal. Pues bien, frente al aburrimiento uno busca cualquier "pasatiempo" (Zeitvertrieb), alguna actividad que acelere el transcurso del tiempo que ha devenido largo. Heidegger considera entonces las distintas formas de aburrimiento desde el más superficial al más profundo, aquél que constituye propiamente el estado de ánimo fundamental.

El "uno se aburre" ("es ist einem langweilig"), nos acerca al aburrimiento más profundo, del cual los otros son sólo variaciones, fruto de la represión que se ejerce constantemente frente al mismo. Este aburrimiento no sorprende súbitamente sin que alguna situación concreta lo movilice.

El tiempo, no como sucesión de ahoras sino como horizonte unitario y total que posibilita la manifestación del ente con sus modos extáticos de temporización pasado, presente y futuro - nos rehúsa. El ser, como experiencia de la totalidad del ente, se da (es gibt) porque el tiempo se manifiesta como aquello que retirándose convierte a todo ente en indiferente. Pero, cuando este horizonte temporal se dilata, anula la existencia, aparece el vacío: el tiempo mismo nos es indiferente, ya no hay un pasado, ni un presente, ni un futuro, sino una inmensa unidad temporal inarticulada.

${ }^{6}$ Langeweile, si bien en alemán indica literalmente un "rato largo" su correcta traducción designa el aburrimiento o el tedio. 
En el "uno se aburre", el sujeto desaparece en ese "uno" haciéndose un nadie indiferente. Pero uno no se aburre ni de esto ni de aquello, ni siquiera de uno mismo, no hay pasatiempo que lo reemplace, más bien habrá un abandono de la existencia donde todo se ha vuelto indiferente. Ahora las cosas parecen abandonarnos aunque estén presentes, ellas nos aburren y por ello nos sentimos vacíos.

La indeterminación afectiva que gravita sobre el Dasein puede provocar que éste devenga tedioso para sí mismo y se manifieste como carga insoportable, como fuga ante la carga.

La imperturbable serenidad, el reprimido disgusto de la ocupación cotidiana, el alternarse de ambos, y la caída en el mal humor, no son ontológicamente una nada, aunque estos fenómenos suelen pasar inadvertidos como lo presuntamente más indiferente y fugaz en el Dasein. Que los estados de ánimo se estropeen y puedan cambiar sólo prueba que el Dasein ya está siempre anímicamente templado. La indeterminación afectiva, a menudo persistente, monótona y descolorida, que no debe ser confundida con el mal humor, no sólo no es una nada, sino que, por el contrario, precisamente en ella el Dasein se vuelve tedioso a sí mismo. En semejante indeterminación afectiva, el ser del Ahí se ha manifestado como carga. (Heidegger, 1997, §29)

En este sentido, en Heidegger es posible señalar un tercer anteproyecto que revela la pesada carga de la existencia. El tedio se presenta como paradigma de los sentimientos cotidianos de indiferencia, que se subsume bajo el concepto de indeterminación afectiva (fahle Ungestimmtheit): indeterminación que abre al propio Ser-ahí (Dasein) y al ente como totalidad, es decir al ser. De este modo, Heidegger profundiza la dirección del Aquinate: es posible la tristeza por las cosas buenas del mundo, tristeza que retorna como molestia por la evitación de una carga. El aburrimiento se convierte en aborrecimiento. La falta de efectividad de ese tiempo nos deja vacíos mientras éste se alarga. Sin embargo, cuando la urgencia y la agudeza se pierden, en ese vacío se abre el propio horizonte temporal en todas sus dimensiones: se anuncian ahora posibilidades que yacían adormecidas precisamente en ese alargamiento del tiempo.

Más aún, ante la "indiferencia" (Gleichgültigkeit) - que también puede mostrarse en la afanosa actividad -, Heidegger plantea la "serenidad" (Gleichmut) como estado de ánimo que surge de la "resolución" (Die Entscheidung), esa mirada instantánea sobre las posibles situaciones del poder-estar-enteramente abierto en el adelantarse hacia la muerte (Heidegger, 1997, §68)

De esta perspectiva, la acedia puede ser considerada como una disposición afectiva que permite la apertura ante nuestro poder-ser, pero también la caída en la impropiedad de nuestro ser, es decir en el ocultamiento de nuestras potencialidades. Como estado afectivo la acedia puede incluir tanto lo extraordinario - como 
apertura del ser - y lo extraño - como la pérdida del sentido de las cosas. Es menester por tanto, recurrir a la serenidad para encontrar el equilibrio que regule estos dos aspectos, so pena que la ansiedad pueda consumir al hombre y revelarle el peso de la existencia de manera insoportable.

Cuando el acidioso niega su trascendencia cosificándose, cae en el tedio para eximirse de la pesadez de la existencia, de ser apelado ante su poder ser. La impunidad frente a esa obligación es lo que retorna como tristeza. La procrastinación ante la responsabilidad por la tarea de darse su ser, de elegirse, lo lleva a afanarse meramente por las cosas que lo rodean, desvía su atención hacia vaciados modo-deser que sólo reproducen lo momentáneo, lo estéril que se agota en si mismo.

La acedia como caída, se encuentra en todos y en cada uno como disposición afectiva, más que un concepto moral o patológico deviene un problema ontológico en cuanto nos abre al ser de una manera particular: es el entretenimiento que se cierne sobre el interés de mi hacer. Constituye una manera de ser que nos aleja de nuestro poder ser, es un mundo árido que nos seduce constantemente y nos atrae hacia lo entretenido e indiferente. La distracción hacia los entes nos permite corrernos de la responsabilidad de comprendernos finitos.

Sin embargo, es desde esa caída que el Dasein ha de procurar el cuidado (Sorge) para habitar en el mundo, para apropiarse de esa tonalidad afectiva.

\section{Cuarto anteproyecto. Paradepresiones y cultura actual}

Digamos claramente que así como la melancolía es la enfermedad tipo de la depresión, la acedia es la figura tutelar de las paradepresiones.

(Charbonneau, 2003, p. 28).

Analizando la sociedad actual, uno también puede visibilizar una trama de fatiga, aburrimiento, vacío, tristeza, a las que Charbonneau y Legrand (2003) designan como paradepresiones. Constituyen un conjunto de problemas a menudo infrasintomáticos, demasiados lábiles y poco significativos para ser denominados síntomas. A estos sentimientos psíquicos y corporales de lasitud, desaliento, de inanidad ante las cosas, de astenia psicógena, estos autores prefieren denominarlos como "constelaciones", considerando a la acedia como figura tutelar de las mismas.

La paradepresiones son fenómenos que se ubicarían como falla de la motivación ante la pérdida de placer por las cosas, o como una dispersión temporal que lleva a recomenzar múltiples tareas sin haber terminado las primeras. Se trata de un vagabundeo en la acción que impide investir con suficiente determinación nuestras acciones. Por su parte, la acedia en cuanto mezcla de pasiones, es más sutil y por lo 
tanto, más peligrosa que la tristeza. Es una mezcla de todas las pasiones, contiene lo irascible y lo concupiscible. A diferencia de la tristeza que es unipolar, la acedia tiene un carácter multipolar ya oscila entre la languidez, la torpeza, el taedium vitae, la indiferencia y el aburrimiento profundo.

El aburrimiento traduce un sentimiento de vacío, de angustia de vivir y de no coincidencia con el mundo, es la a-tonalidad con el mundo; patentiza el habitar el mundo en forma de malestar. Precisamente, ciertas adaptaciones caracterizadas por un trato "superficial" con el mundo, impiden el desarrollo de un profundo compromiso con las personas y situaciones. ${ }^{7}$ Los hechos, al tornarse estimulantes o excitantes, dotados de un matiz fulgurante, vuelven indolente al sujeto frente a cualquier actividad. Lo interesante se disuelve en lo indiferente, dando lugar a otro entretenimiento (tener-entre) que acaba en aburrimiento y pérdida de agrado en la tarea.

El tener-entre del entretenimiento, lo interesante, dice referencia a un mundo tomado como objeto que se nos presenta sugestivo pero es estéril para configurarnos en nuestro ser. Al contrario, el interés es un verdadero "estar mezclado en", un formar -parte, un involucrarse por completo con algo que otorga peso ontológico al hacer.

De allí que el interés y lo interesante, se diferencien más allá de la raíz etimológica. En lo interesante, todo se agota, se consume y así pierde su peso, no puede ser habitado por el ser porque solo hay un regocijo momentáneo de lo rutilante. 62 Este momento álgido al que lo interesante trata de atrapar (tener-entre), no puede más que marchitarse dado el esfuerzo que implica el sujetar-se pasivamente de ese contenido gaseoso, evanescente que lo caracteriza.

En cambio, el interés no encuentra agotamiento; de él se puede obtener un encuentro y una pérdida; se puede sostenerlo o abandonarlo, pero no se dan condiciones de vaciamiento. El interés ubica al cuerpo en acción y lo carga de sentido, y su pérdida nos conduce a la acedia como un no-sentido en Dios. Este no-sentido por el abandono del interés nos arroja en las fronteras de lo interesante y por decantación al aburrimiento. Lo interesante es la contratara del interés, su negativo.

Como señala G. Agamben (1995, pp. 62-63), la acedia no es sólo una fuga de..., sino también una fuga por..., que comunica con su objeto bajo la forma de negación y de carencia. Es una fuga a causa de la pesadez de lo trascendental, que es vivenciado como amenazante. Es la pérdida de aquello por lo que se consagra, de aquello que es su proyecto, su hacer. La existencia se torna vaciada ya que no existe un sentido que la sustente, se da una fuga de lo trascendental a lo inmediato, por el

${ }^{7}$ El termino interés (inter-esse) significa estar mezclado y entre las cosas, y quedarse con ella. Lo interesante es aquello en un instante puede ser indiferente y ser suplantado por otra cosa. Este desplazamiento de lo interesante a lo indiferente, conduce indudablemente al aburrimiento. 


\section{ARTIGOS}

propio peso de lo infinito. Se diluye en ser-tras-el-mundo y por-el-mundo (cosificación del mundo). No vive en el mundo, sino con el mundo, camuflado entre entes en una existencia inauténtica y en ese intento de dominar el futuro de incertidumbres, se aferra a la presentificación instantánea.

Todavía más "La acedía moderna ya no es soledad claustral - aunque todos llevamos un claustro en el alma, sino el vacío y el espanto frente a un Dios lelo y abandonado" (Cioran, 1994, p. 84).

\section{La paciencia como perseverancia}

La paciencia es la virtud que se experimenta en la duración y corresponde a una disposición a acoger, con toda pasividad pero con clarividencia el momento presente. La paciencia, como antídoto mantiene el ritmo temporal propio de la perseverancia, es decir ese avance lento pero seguro en el conocimiento de la experiencia de si mismo.

(Depraz, 2003b, pp. 14-16).

Para contrarrestar la acedia, ese tedium o anxietas cordis, Casiano propone la paciencia (hypomené), precisamente porque entre ambas hay una dinámica temporal participada, común. Por un lado, la acedia en tanto aflojamiento o hundimiento muestra una duración herida, mientras la paciencia hecha de perseverancia expresa una duración sedimentada donde se juegan la estabilidad y la resistencia.

En efecto, la paciencia requiere esfuerzo y aprendizaje: no se es espontáneamente paciente, ni se logra ello de golpe. La paciencia, vivida y sufrida, exige para ser integrada que una parte íntima de cada uno sea reapropiada a partir de un largo trabajo.

Pero también la paciencia implica una versión hacia lo otro, señala Levinas, y con ello un reconfigurar la noción de tiempo. Experimentado como paciencia, el tiempo tiene como condición de posibilidad la relación con la alteridad. Es la paciencia auténtica de algo que puede acontecer más allá de toda pre-visión o proyecto propio.

El sujeto es consciente que dicho tiempo excede su temporalidad finita, y que siendo para-el-Otro, existe en la modalidad del para-más-allá-de-la-muerte, y por tanto como apertura a la esperanza. Si el hombre no se relacionase con lo Otro que quiebra su ahora e introduce lo nuevo en el flujo del tiempo, su temporalidad se reduciría a la constante prolongación extática de un único ahora. Sólo entonces el tiempo como paciencia puede convertirse en espera de algo Otro que adviene. 
La paciencia abierta a esperar más allá de la muerte, no se identifica con la nada y su ahora tampoco es el fin del tiempo. El sujeto puede ser absolutamente paciente ante la muerte, porque sabe que el tiempo es más que aquello que él puede proyectar, es más que su temporalidad que culmina con la muerte. Una muerte pensada ahora a partir del tiempo abierto a lo infinito (diacronía) y no partir de tiempo clausurado de la finitud (sincronía).

Por eso, como respuesta

... frente al nihilismo heroico con que el Dasein anticipa su propia muerte, la meditación levinasiana propone una superación ética de la muerte: en tanto que obediencia al Otro, la paciencia posibilita un tiempo tras mi muerte en el que el sentido vence la insensatez del morir. (Sucasas, 2006, p. 275)

\section{Referencias}

Agamben, G. (1995). Estancias. La palabra y el fantasma en la cultura occidental. Valencia: PRE-Textos.

Angelini, G. (2004). La acedia y la virtud. In Las virtudes y la Fe (pp. 41-66). Madrid: Cristiandad.

Aquino, T. de (2010). Suma Theologica. Vol. II, III y IV. Madrid: BAC.

Aristóteles (2004). Problemas. In Obras Completas. Madrid: Editorial Gredos.

Bartra, R. (2005). El duelo de los ángeles. Locura sublime, tedio y melancolía en el pensamiento moderno. Buenos Aires: FCE.

Casiano, J. (1957). Instituciones. Madrid: Ed. Rialp.

Charbonneau, G., \& Legrand, J.M. (2003). Dépressions et paradépressions. Clinique, psychopatologique et thérapeutique des manifestations paradepréssives. Paris: Le Cercle Herméneutique.

Charbonneau, G. (2003). Les manifestations paradépresives. L'acédie entre fatigue et ennui. In G. Charbonneau, \& J. M. Legrand (ed.), Dépressions et paradépressions. Clinique, psychopatologique et thérapeutique des manifestations paradepréssives (pp. 27-34). Paris: Le Cercle Herméneutique.

Cioran, E. (1994). De lágrimas y de santos. Barcelona: Tusquets.

Conti, N.A. (2006). Entre el pecado y la melancolía: la acedia en la Edad media. VI Congreso Mundial de Estados Depresivos; Simposium internacional de desórdenes adictivos, Septiembre. Mendoza, Argentina.

De la Cruz Valles, A. (2007). Tiempo técnico y estados afectivos. Astrolabio. Revista internacional de filosofía, 4, 30-42.

Debray, Q. (2003). Preface. In G. Charbonneau, G., \& J. M. Legrand. Dépressions et paradépressions (pp. 11-14). Paris: Le Cercle Herméneutique. 


\section{ARTIGOS}

Depraz, N. (2003). Acédie et patience, fluctuación emotionelle et temporalité de l'instant. In Dépressions et paradépressions (pp. 11-12). Paris: Le Cercle Herméneutique.

Evagrio Póntico (2010). Sobre los ocho vicios malvados [Recuperado em 02/12/2010, de $<\mathrm{http}$ :/www.franciscanos.net/patristica/textos/evagrio\%20pontico.htm>.

Forthomme, B. (2003a, avril). Phénoménologie romanesque de l'acédie. Le dandy et el bohème: deux figures modernes de l'acédie. Le Cercle Herméneutique, 1, 27-33.

Forthomme, B. (2003b). L'acédie, la dépression, la mélancolie et l'ennui. In G. Charbonneau, \& J. M. Legrand. Dépressions et paradépressions (pp. 21-26). Paris: Le Cercle Herméneutique.

Granger, B., \& Charbonneau, G. (ed) (2003). Phénoménologie des sentiments corporels. Vol. II - Fatigue, lassitude, ennui. Paris: Le Cercle Herméneutique.

Heidegger, M. (1955). ¿Qué es la metafisica? Madrid: Alpes.

Heidegger, M. (1966). Introducción a la metafísica. Buenos Aires: Nova.

Heidegger, M. (1997). Ser y tiempo. Santiago de Chile: Universitaria.

Heidegger, M. (2007). Los conceptos fundamentales de la metafisica: mundo, finitud, soledad. Madrid: Alianza.

Hughet, M. (2003). L'ennui entre philosophie et psychopathologie. In G. Charbonneau, \& J. M. Legrand. Dépressions et paradépressions (pp. 35-40). Paris: Le Cercle Herméneutique.

Jankélévich, V. (1963). L'aventure, l'ennui, le sérieux. Paris: Aubier-Montagne.

Larchet, J.C. (1992). Thérapeutique des maladies mentales. L'expérience de l'Orient chrétien des premiers siècles. Paris: Du Cerf.

Lauand, J. (2004, setembro). O pecado capital da acídia na análise de Tomás de Aquino Notas de conferência proferida no Seminário Internacional Os Pecados Capitais na Idade Média, Univ. Fed. do Rio Grande do Sul, setembro de 2004. Recuperado em 03/08/2012 de <http://www.hottopos.com/videtur28/ljacidia.htm->.

Legrand, J.M. (2003a). L'acédie: de la théologie à la philosophie morale. In G. Charbonneau, \& J.M. Legrand, Dépressions et paradépressions (pp. 98-127). Paris: Le Cercle Herméneutique.

Legrand, J.M. (2003b). L'ennui n'est pas dépressif. In G. Charbonneau, \& J.M. Legrand, Dépressions et paradépressions (pp. 55-62). Paris: Le Cercle Herméneutique.

Levinas, E. (1993). Dios, la muerte y el tiempo. Madrid: Cátedra.

Leroy-Viemont, B. (2003). Au discours de 'à quoi-bon du dépressif'. In G. Charbonneau, \& J.M. Legrand, Dépressions et paradépressions (pp. 69-76). Paris: Le Cercle Herméneutique.

Lesmas González, D. (2009). Uno se aburre: Heidegger y la filosofía del tedio. Bajo palabra, revista de filosofia, 4, 167-172.

López-Ibor Aliño, J.J.; Ortiz Alonzo, T., \& López Ibor Alcocer, M. I. (1999). Genio y locura. In Lecciones de Psicología Médica (p. 110). Barcelona: Masson

Madioni, F. (2001). Contribution à l'étude clinique et psychopalogique du syndrome de fatigue chronique. Annales Médico-psychologiques, 159, 431-436. 
Madioni, Fr. (2003). La fatigue entre la dimension existentielle et approche clinique. In G. Charbonneau, \& J.M. Legrand, Dépressions et paradépressions (pp. 41-48). Paris: Le Cercle Herméneutique.

Madioni, F. (2006). Eloge de l'ennui. Une étude de phénoménologie et de psychopathologie. Le Cercle Herméneutique, 7, 124-132.

Maggini, C.Y., \& Dalle Lucche, R. (1991). Il paradiso e la noia. Riflessionei metapsicologiche sulla noia morobsa. Torino: Bollati Boringheri.

Magtaz, A.C., \& Berlinck, M.T. (2010, $1^{\circ}$ semestre). Distúrbios da oralidade na melancolia: a acídia como estagnação. Trivium, II, 276-289.

Manzanedo, M.F. (2004). Clasificación de las pasiones. In Las pasiones según Santo Tomás (pp. 32-42). Salamanca: San Esteban.

Martinez Hernandez, J. (1995). La experiencia trágica de la muerte. Murcia: Universidad de Murcia.

Moreno Claros, L. F. (2002). Martin Heidegger, filósofo del ser. Madrid: Edaf.

Pieper, J. (1976). Virtudes fundamentales. Madrid: Rialp.

Pocai, R. (2005). Introducción a Theunissen, M. In Anteproyecto de modernidad: antigua melancolía y acedia de la Edad Media (pp. 7-17). Valencia: Colección Náyade.

Richir, M. (1992). Phénoménologie et psychiatrie: d'une division interne à la Stimmung. Etudes Phénoménologiques, 8(15), 81-117.

66 Rovaletti, M. L. (1994). Fenomenología, culpa y depresión. In M.L. Rovaletti (ed), Psicología y psiquiatría fenomenológica (pp. 169-188). Buenos Aires: Cátedra de Psicología Fenomenológica y Existencial de la Universidad de Buenos Aires-Biblos.

Rovaletti, M. L. (1997). La angustia o la palabra hecha síntoma. Revista de Filosofía, México, 89, 188-214.

Rovaletti, M. L. (2005, marzo). Fragilidad y fiabilidad en las sociedades post-industriales. Revista de Psicología, 1(1), 75-87.

Sucasas, A. (2006). Levinas: lectura de un palimpsesto. Buenos Aires: Ed. Lilmod. Prologo de M. Reyes Mate.

Theunissen, M. (2005). Anteproyecto de modernidad: antigua melancolía y acedia de la Edad Media. Valencia: Colección Náyade.

Ulliac, G. (2003). L'experience du nihilisme et la psychopatologie. In G. nCharboneau, \& J.M. Legrand, Dépressions et paradépressions (pp. 83-86). Paris: Le Cercle Herméneutique. 


\section{ARTIGOS}

\section{Resumen}

(A acedia como forma de mal-estar na sociedade atual)

Partindo da proposta de Theunissen, procura-se realizar uma regressão arqueológica a respeito do conceito de melancolia na antiguidade e de acedia na Idade Média. Com isso, tenta-se refletir a respeito da trama constituida pela fadiga, tédio, aborrecimento, tristeza que se entretece na cultura atual. Charbonneau e Legrand (2003) designam como paradepressões esse conjunto de problemas, frequentemente, infrassintomáticos, muito lábeis e pouco significativos para serem denominados sintomas.

Palavras chave: Melancolía, acedia, tédio, sociedade moderna

\section{(Acedia as a form of mental illness in today's society)}

Based on Theunissen's proposition, we carried out an archeological investigation into the concept of melancholia in the ancient world and acedia in medieval times. In doing so we compare the concept to fatigue, boredom and sadness found in today's the culture. Charbonneau and Legrand (2003) called these problems paradepressions of problems, often infra-symptomatic and too transient and insignificant to be described as symptoms.

Key words: Melancholia, acedia, boredom society

\section{(L'acédie comme type de mal-être de la société contemporaine)}

En prenant comme point de départ le propos avancé par Theunissen, cet article a pour but de faire un retour archéologique sur le concept de mélancolie dans L'Antiquité et d'acédie au Moyen âge. Il propose donc une réflexion sur la fatigue, l'ennui, la tristesse qui imprègne la culture contemporaine. Charbonneau et Legrand (2003) désignent comme paradépressions un ensemble de problèmes souvent infra-symptomatiques, trop passagers et trop peu significatifs pour être considérés comme symptômes.

Mots clés: Mélancolie, acédie, ennui, société moderne

(Verbitterung als eine Form des Unwohlseins in der heutigen Gesellschaft)

Ausgehend von Theunissens Ansatz, wird hier der Versuch einer archäologischen Regression zum Begriff der Melancholie im Altertum und der Verbitterung im Mittelalter durchgeführt. Dies dient der Reflexion über den Zusammenhang von Müdigkeit, Verdruss, Gereiztheit und Traurigkeit, die die heutige Kultur durchziehen. Charbonneau und Legrand (2003) bezeichnen diese Problematik als "Paradepressionen", oft als infrasymptomatisch, weil sie zu labil und unbedeutsam sind, um als Symptome bezeichnet zu werden.

Schlüsselwörter: Melancholie, Verbitterung, Verdruss, moderne Gesellschaft 
Citação/Citation: Rovaletti, M. L., \& Pallares, M. (2014, março). La acedia como forma de malestar en la sociedad actual. Revista Latinoamericana de Psicopatologia Fundamental, 17(1), 51-68.

Editor do artigo/Editor: Prof. Dr. Manoel Tosta Berlinck

Recebido/Received: 8.12.2012/ 12.8.2012 Aceito/Accepted: 5.2.2013 / 2.5.2013

Copyright: (C) 2009 Associação Universitária de Pesquisa em Psicopatologia Fundamental/ University Association for Research in Fundamental Psychopathology. Este é um artigo de livre acesso, que permite uso irrestrito, distribuição e reprodução em qualquer meio, desde que o autor e a fonte sejam citados / This is an open-access article, which permits unrestricted use, distribution, and reproduction in any medium, provided the original author and source are credited.

Financiamento/Funding: Os autores declaram não ter sido financiadas ou apoiados / The authors have no support or funding to report.

Conflito de interesses/Conflict of interest: Os autores declaram que não há conflito de interesses / The authors declare that has no conflict of interest.

\section{María Lucrecia Rovaletti}

Dra. en Filosofía, Licenciada en Psicología y Docente Autorizada en Medicina; Profesora Emérita de la Universidad de Buenos Aires - UBA (Buenos Aires, Ar); Fue Profesora Regular Titular de "Psicologia Fenomenológica y Existencial" y "Psicología, Ética y Derechos Humanos", en la Facultad de Psicología de esa casa de estudios; Investigadora Principal del Consejo Nacional de Investigaciones Científicas y Técnicas (CONICET); Investigador-Docente categoria 1; Presenta innumerables publicaciones nacionales e internacionales; Directora de Proyectos de Investigaciones, en UBA, CONICET y ANPCYT (Buenos Aires, Ar).

Juramento $1453,4^{\circ}$ piso Dto 29

(1428) Buenos Aires, Argentina

Fone: (+5411) 4783-9110

e-mail: mlrova@arnet.com.ar/mlrova@psi.uba.ar/mlrova@conicet.gob.ar

\section{Martín Pallares}

Estudiante avanzado en la carrera de Psicología en la Universidad de Buenos Aires - UBA (Buenos Aires, Ar); Obtuvo premios en 2010 y 2011 al mejor trabajo presentado a las Jornadas internacionales de Investigación (Psicología, UBA); Es investigador en formación de los proyectos de la UBA desde 2010.

Colón 757 - Remedios de Escalada - Lanús (1826)

Provincia de Buenos Aires-Argentina

Fone: (+5411) 4248-7417

e-mail: martinpallares_10@yahoo.com.ar,,, 